stripe formation in Drosophila may be a late evolutionary modification of a genuine patterning process that can be observed in very different developmental situations, including those found in Drosophila itself.

But the stripes on the fish still call for more explanation: those shown in Fig. 1 of the paper by Kondo and Asai ${ }^{1}$ are very narrow with respect to the spaces in between. All the models I know of can only produce stripes and interstripes of the same size.

Hans Meinhardt is in the Max-PlanckInstitut für Entwicklungsbiologie, Spemannstrasse 35, 72076 Tübingen, Germany.

\title{
The scattered jigsaw
}

\section{Richard Warn}

EVERY so often a new piece of scientific jigsaw fills a gap in the puzzle. One such piece is the paper by Bladt et al. ${ }^{1}$ on page 768 of this issue, which identifies the c-met/scatter factor signalling system as the controller of muscle precursor cell migration in mouse embryonic limb buds.

Scatter factor, also called hepatocyte growth factor $(\mathrm{SF} / \mathrm{HGF})$, is a member of the blood serine-protease family, ${ }^{2,3}$. It resembles blood plasminogen in both its structure and its mechanism of activation, but lacks any enzyme activity. Its receptor is encoded by c-met, a transmembrane protein with a cytoplasmic tyrosine kinase domain ${ }^{4,5}$.

The scatter factor/c-met signalling system is now known to have several biological functions. One relates to a previous striking finding that scatter factor acting at c-met induces epithelial cell colonies of various types to dissociate or scatter in vitro by rupturing cell-cell junctions and enhancing cell motility ${ }^{6,7}$. The scattered cells will move up a concentration gradient of the factor. Scattering is usually induced through a paracrine signalling mechanism: mesenchymal cells such as fibroblasts secrete scatter factor and epithelial cells (such as kidney or lung) expressing c-met receptors respond to it.

For any result observed in a Petri dish, the big question is whether there is a corresponding biological phenomenon in vivo. To investigate this, Bladt et al. ${ }^{1}$ created mouse embryos lacking a functional c-met gene and therefore the kinase activity, and determined which structures failed to form. In such embryos the future limb-bud myoblasts failed to detach from the precursor somite blocks and never migrated, although the somite muscles themselves differentiated. In normal control embryos the myogenic precursors about to migrate showed strong c-met expression. At this time, mesenchymal cells within the limb buds express scatter factor. The conclusion is that scatter factor, secreted from within the limb bud, diffuses locally and induces muscle precursor cells to detach from the somite edges and to migrate up the concentration gradient. A similar failure of migration was found for the muscle pro- genitors of the diaphragm and the tip of the tongue.

Because scatter factor is also a potent mitogen for many epithelial cell types in vitro, it was predictable that some failure of tissue formation apart from muscle would be found. A marked reduction in liver and placenta size is reported by Bladt et al. ${ }^{1}$, coupled with a large reduction in the number of liver parenchymal cells and placental trophoblast cells in c-met-negative embryos. The results are identical to those described for mouse embryos lacking scatter factor ${ }^{8,9}$ and demonstrate that the factor has a major function in forming these tissues.

There is also evidence that the duo of scatter factor and c-met is involved in the morphogenesis of many other organs. This has been particularly well documented for the kidney and the mammary gland. As for the mouse limb, the initial findings came from work with cultured cell lines. If MDCK kidney cells are cultured on top of collagen gels and scatter factor is added, cells scatter and invade the gel ${ }^{10}$. But if the same cells are grown inside the gel in the presence of scatter factor, extensive tubulogenesis results, with the appearance of structures in which polarized cells border a lumen ${ }^{11}$. Very similar results were obtained with mammary gland cells ${ }^{12}$. It appears that the cells respond to scatter factor in almost opposite ways, depending on spatial and other differences in the extracellular environment.

There is now good evidence that these effects are not tissue culture artefacts but that they mirror morphogenesis in vitro. The addition of scatter factor antibodies to metanephric kidney rudiments grown in serum-free organ culture inhibited the normal branching of the uretic bud rudiment ${ }^{13}$. Scatter factor was expressed in vivo by the metanephric mesenchyme and cmet was fairly strongly expressed in the cells of the ureteric bud, suggesting a paracrine induction of tubule formation.

Organ culture has also demonstrated that the scatter factor/c-met signalling system has a major function in the development of the mammary gland ${ }^{14}$. Furthermore, it acts in sequence with and in complementary fashion to neuregulin, a member of the EGF family, to induce complete differentiation. Addition of SF/HGF to mouse mammary gland tissue in culture promoted branching of the ducts in much the same way as occurs in vivo during its differentiation. It also inhibited secretory protein production. In contrast, neuregulin promotes budding of mammary alveoli and milk protein secretion.

The effects seen in organ culture are paralleled by those in vivo. Scatter factor expression occurs throughout mammary gland development in virgin mice and reaches a peak at the time of ductal differentiation; levels then fall during pregnancy and lactation. In contrast, virtually no neuregulin is synthesized in virgin animals but there is a large increase during pregnancy.

In conclusion, the varied effects of scatter factor in vitro can now be related to diverse functions in vivo during embryogenesis. These effects all seem to be mediated through a paracrine effector system, but there are jigsaw pieces related to possible autocrine functions of scatter factor that do not yet fit to form a picture. Cotransfection of human c-met and scatter factor genes into murine 3T3 fibroblasts produces cell lines that become tumorigenic when transplanted into nude mice ${ }^{15}$. The transplanted cells show areas of epithelial cell-like differentiation with cell-cell junctions and the presence of tubule lumens. Co-expression of markers for mesenchymal (vimentin) and epithelial (keratin) cell types occurs within the cells. These changes resemble the mesenchymal-to-epithelial transition of cells that occurs during the morphogenesis of a number of organs, including the kidney. Cell lines expressing both c-met and scatter factor have been derived from the early stage renal mesenchyme of mouse embryos $^{13}$. But the possible functions of $\mathrm{SF} / \mathrm{HGF} / \mathrm{c}-$ met signalling in such autocrine situations remain to be elucidated.

Richard Warn is in the School of Biological Sciences, University of East Anglia, Norwich NR4 7TJ, UK.

\footnotetext{
1. Bladt, F., Riethmacher, D., Isenmann, S., Aguzzi, A. \& Birchmeier, C. Nature 376, 768-771 (1995).

2. Miyazawa, K. et al. Biochem. biophys. Res. Commun. 163, 967-973 (1989).

3. Nakamura, T. et al. Nature 342, 440-443 (1989)

4. Naldini, L. et al. Oncogene 6, 501-504 (1991).

5. Bottaro, D. P. et al. Science 251, 802-804 (1991).

5. Bottaro, D. P. et al. Science 251, 802-804 (1991).
6. Stoker, M., Gheradi, E., Perryman, M. \& Gray, J. Nature 327, 239-242 (1987).

7. Gherardi, E., Gray, J., Stoker, M., Perryman, M. \& Furlong, R. Proc. natn. Acad. Sci. U.S.A. 86, 5844-5848 (1989)

8. Schmidt, C. et al. Nature 373, 699-702 (1995).

9. Uehara, Y. et al. Nature 373, 702-705 (1995)

10. Weidner, K. M., Behrens, J., Vandekerckhove, J. \& Birchmeier, W. J. Cell Biol. 111, 2097-2108 (1990). 11. Montesano, R., Matsumoto, K., Nakamura, T. \& Orci, L. Cell 67, 901-908 (1991)

12. Soriano, J. V., Pepper, M. S., Nakamura, T. \& Montesano, R. J. Cell Sci. 108, 413-430 (1995).

13. Woolf. A. S. et al. J. Cell Biol. 128, 171-191 (1995).

14. Yang, Y. et al. J. Cell Biol. (in the press).

15. Tsarfaty, I. et al. Science 263, 98-101 (1994).
} 